\title{
Natural History of Postoperative Nonfunctioning Pituitary Adenomas: A Systematic Review and Meta-Analysis
}

\author{
Yong Chen ${ }^{a} b$ Cheng De Wang ${ }^{a}$ Zhi Peng Su ${ }^{a}$ Yun Xiang Chen ${ }^{a} \quad$ Lin Cai $^{a}$ \\ Qi Chuan Zhuge ${ }^{\mathrm{a}}$ Zhe Bao $\mathrm{Wu}^{\mathrm{a}, \mathrm{c}}$ \\ a Department of Neurosurgery, First Affiliated Hospital of Wenzhou Medical College, Wenzhou, bepartment of \\ Neurosurgery, Yueyang Second People's Hospital, Yueyang, and 'Department of Neurosurgery, Huashan Hospital, \\ Fudan University, Shanghai, China
}

\section{Key Words}

Nonfunctioning pituitary adenomas • Pituitary adenomas • Natural history $\cdot$ Meta-analysis $\cdot$ Tumor volume doubling time $\cdot$ Tumor growth-free survival rate

\begin{abstract}
Objective: Previous studies attempting to define the natural history of postoperative nonfunctioning pituitary adenomas (pNFPAs) were somewhat limited by selection bias and/ or small numbers and/or lack of consistency among the study findings. The aim of this study was to scrutinize the literature in order to analyze the natural history of pNFPAs. Methods: Electronic database including MEDLINE, PubMed and Cochrane CENTRAL were searched. The literature relating to the patients with pNFPAs without postoperative radiotherapy and pharmacotherapy was collected. Eligible studies reported on the rate of tumor recurrence, the tumor growth-free survival rate (TGFSR) at 5 and 10 years, and/or the residual tumor volume doubling time (TVDT). Results: 19 studies met the criteria. The pNFPAs were divided into two groups: the pooled recurrence rate of group I without detectable residual tumor (371 patients) was $12 \%(95 \% \mathrm{Cl}$ 6-19\%), the TGFSR at 5 and 10 years were $96 \%$ (95\% Cl 89$99 \%$ ) and $82 \%(95 \% \mathrm{Cl} 65-94 \%)$, respectively. The pooled recurrence rate of group II with residual tumor (600 patients)
\end{abstract}

was $46 \%$ (95\% Cl 36-56\%), the TGFSR at 5 and 10 years were $56 \%(95 \% \mathrm{Cl} 41-71 \%)$ and $40 \%$ (95\% Cl 27-53\%), respectively. The mean TVDT was 3.4 years $(95 \% \mathrm{Cl} 2.4-4.5$ years). Conclusions: pNFPAs, with or without detectable residual tumor, need stratification of treatment and radiological/endocrinological follow-up strategy. According to the TVDT, residual tumor regrowth is very slow, which permits an extensive and safe follow-up program for most patients.

Copyright $\odot 2012$ S. Karger AG, Basel

\section{Introduction}

Pituitary adenomas represent $10-20 \%$ of all primary brain tumors [1]. Clinically, nonfunctioning pituitary adenomas (NFPAs) make up approximately one third of pituitary adenomas. At diagnosis most of the tumors are macroadenomas, and the patients present with symptoms caused by pituitary hormonal insufficiencies and/or the tumor expansion, i.e. headache and decreased vision. The primary treatment of patients with NFPAs is pituitary microsurgery with transsphenoidal or transcranial

Yong Chen and Cheng De Wang contributed equally to this work.

\section{KARGER}

Fax +4161306 1234

E-Mail karger@karger.ch

www.karger.com
(C) 2012 S. Karger AG, Basel

0028-3835/12/0964-0333\$38.00/0

Accessible online at:

www.karger.com/nen
Zhe Bao Wu

Department of Neurosurgery

First Affiliated Hospital of Wenzhou Medical College

Wenzhou 325000 (China)

Tel. +865778806 9309, E-Mail zhebaowu@yahoo.com.cn 
approach to achieve a rapid reduction of tumor volume and decompression of the optic apparatus.

Significant tumor debulking improves visual field disorders in $80 \%$ of patients and relieves headaches in almost every case [2]. However, during long-term follow-up after transsphenoidal surgery, there is tumor regrowth in 12$46 \%$ of the patients [3-6]. Medical therapy with dopamine agonists or somatostatin analogs has a variable and often limited impact on the risk of recurrence [7]. Although dopamine agonist treatment was associated with tumour size decrease in $33 \%$ of the patients in the recent report by Greenman et al. [8], medical therapy has not been used on a routine basis for postoperative nonfunctioning pituitary adenomas (pNFPAs).

Some centers provide postoperative radiotherapy in selected patients to prevent tumor regrowth [6, 9-11]. In pNFPAs, pituitary conventional radiotherapy significantly reduces the risk of tumor regrowth with recurrence-free survival of between 87.5 and $97 \%$ at 10 years and between 72 and $92 \%$ at 20 years [6, 12-17], but this approach carries a risk of complications such as hypopituitarism [18]. Irradiation results in hypopituitarism in at least $40-50 \%$ of the patients $[13,19,20]$ and visual complications are reported in $1-3 \%[13,19,21,22]$, along with cerebrovascular disease $[23,24]$ and potential neurocognitive dysfunction [25]. In spite of a low incidence, the relative risk of patients developing secondary tumors, such as gliomas, astrocytoma or sarcoma, is significantly increased [21, 22, 26, 27].

The new treatment modalities of radiosurgery have recently gained interest for the treatment of pNFPAs. The application of radiosurgery (or 'stereotactic radiosurgery') in case of residual or recurrent disease after surgical treatment leads to tumor control in more than $90 \%$ of all patients [28-33]. Because most patient series have only a relatively short duration of follow-up, the long-term effects of stereotactic radiosurgery on pituitary function and visual function have not yet been established in full detail. The major advantage of stereotactic radiosurgery compared with fractionated radiotherapy seems to be a lower risk of side effects, including a lower incidence of hypopituitarism (0-36\%), visual deterioration (0-4\%) and radiation-induced neoplasia [34-37].

So, it is controversial whether early postoperative radiation therapy should be given to prevent recurrence, and whether an early reoperation should be performed for residual adenomas, because we have little information about the natural history of pNFPAs. Those reports $[3,5,9,11$, $16,38-44]$ about the natural history of pNFPAs, however, are limited by small sample sizes, retrospective and non- randomized study designs, heterogeneous patient populations, and varying definitions of outcomes. There is no multicenter meta-analysis summarizing the evidence regarding the knowledge of natural history of pNFPAs and prognostic factors associated with poor outcomes of pNFPAs that would help to formulate clinical practice guidelines. Pooling of the individual series in the form of a systematic review and meta-analysis allows for an improved understanding of the natural history of the pNFPAs.

In this study, the pNFPAs were divided into two groups: patients with or without detectable residual tumors. We wanted to clearly understand the natural history through a systematic review and gain reliable evidence related to tumor regrowth or recurrence, which could provide the foundation for treatment and follow-up strategy.

\section{Methods}

\section{Search Strategy}

English literatures published in MEDLINE, PubMed and Cochrane CENTRAL databases from 1966 to January 2011 were systematically searched using the following terms: 'non functional pituitary tumors'; 'nonfunctioning pituitary adenomas'; 'nonfunctional pituitary macroadenomas'; 'non-functioning pituitary adenoma'; 'non-function pituitary tumors'; 'nonfunctioning pituitary macroadenomas'; 'nonsecreting pituitary adenomas'; 'nonsecreting pituitary adenomas'; 'nonfunctional adenomas of the pituitary gland'; 'non secreting pituitary adenomas', and 'the natural history of surgically treated'. The 'related articles' function was used to obtain any relevant articles. Additionally, the references of the articles included in the analysis were reviewed for any other citations. The search was performed independently by 2 members of the study team: Cheng De Wang and Yong Chen. Hand-searching was conducted using references from papers acquired using the computer searches.

\section{Inclusion/Exclusion Criteria}

Inclusion criteria included purely pNFPAs, which did not have systematic post-operative pituitary radiotherapy and pharmacotherapy. These studies can provide growth parameters of natural history of pNFPAs, such as the rate of tumor recurrence, the tumor growth-free survival rate (TGFSR) at 5 and 10 years and the residual tumor volume doubling time (TVDT). Eligible study designs included retrospective and prospective.

Data from the articles obtained were extracted independently by 2 co-authors and were reviewed by corresponding authors. Data collected from the articles included the number of patients, study design (retrospective and prospective), the postoperative state of tumor recurrence (no detectable residual tumor vs. residual tumor), TGFSR at 5 and 10 years and the residual TVDT. If articles could not provide the parameters directly, we indirectly extracted those parameters from the Kaplan-Meier curves of their articles. We contacted authors for missing data when needed. If no data were reported on a certain variable of interest, they were recorded as not available. 


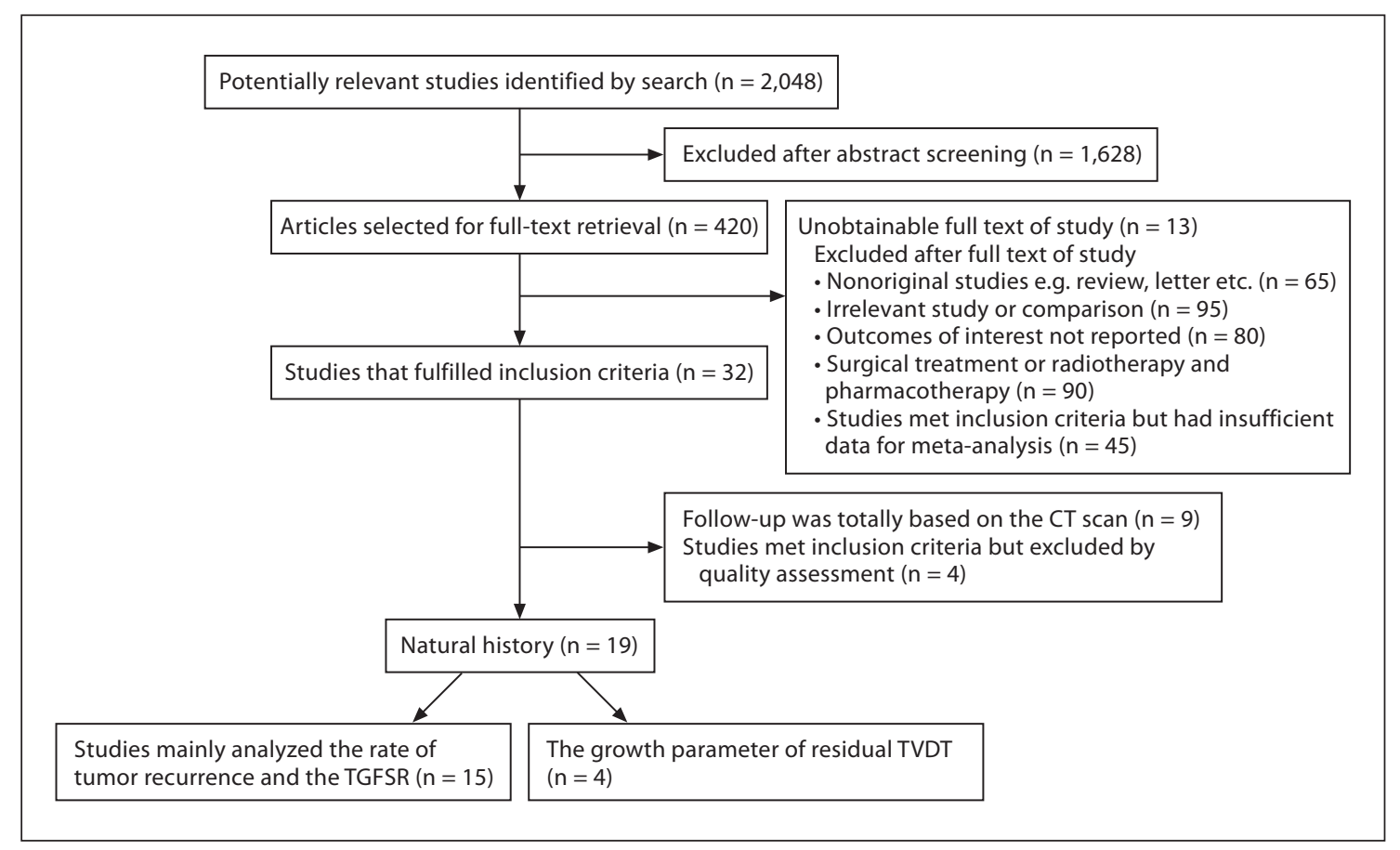

Fig. 1. Study selection process.

\section{Evaluating Quality of Studies}

This study adhered to the reporting guidelines of meta-analysis $[45,46]$ and used the GRADE approach to rate the quality of evidence [47]. To assess the methodological quality of the studies, we determined items such as: ascertainment of outcomes, followup protocol including first time images after surgery, definition of increase in tumor size, MR information (Tesla, slice thickness, with enhancement, etc.) and image reviewers [48].

\section{Statistical Analysis}

Weighted summaries were determined using meta-analysis models if a given result was reported by $\geq 4$ studies. Tests for heterogeneity were performed for each meta-analysis using the $\mathrm{I}^{2}$ statistic ( $\mathrm{I}^{2}$ less than $25 \%$ and $\mathrm{I}^{2}$ greater than $50 \%$ reflect small and large inconsistency, respectively). If the $Q$ value ( $p>0.01$ ) was not significant in the heterogeneity test, it showed that the research was not heterogeneous, so we used fixed-effects models, or else we used random-effects models. The $\mathrm{R}$ meta package from the $\mathrm{R}$ statistical language for Windows was used to perform these analyses [49].

\section{Results}

\section{Search Results}

The data abstraction process was shown in figure 1 . The search identified 2,048 candidate references, of which 32 were studies deemed eligible [2-6, 9-11, 38-44,
50-66]. We excluded 9 studies [3, 4, 43, 50-55] because the case identification was done using single older CT scan techniques that were not comparable with current MRI studies. Three studies did not provide enough information of the natural history of pNFPAs $[2,10,64]$ for this review and one study had few patients $(n=3)$ without postoperative radiotherapy [63]. Additionally, we excluded those 4 studies from this analysis due to the poor quality assessment $[2,10,63,64]$.

\section{Study Characteristics}

Finally, 19 studies met inclusion criteria and the total number of patients included in this meta-analysis was 1,614 , seen in table 1 . These studies were longitudinal observational cohort studies, including prospective (9 studies) and retrospective (10 studies). All patients had pNFPAs who did not have systematic postoperative pituitary radiotherapy and pharmacotherapy. 15 of 19 studies mainly analyzed the rate of tumor recurrence and the TGFSR at 5 and 10 years (table 2), and 4 of 19 studies calculated the growth parameter of residual TVDT (fig. 2). Stratified data were available for a total of 371 patients without detectable postoperative residual tumor and 600 patients with residual tumor. 


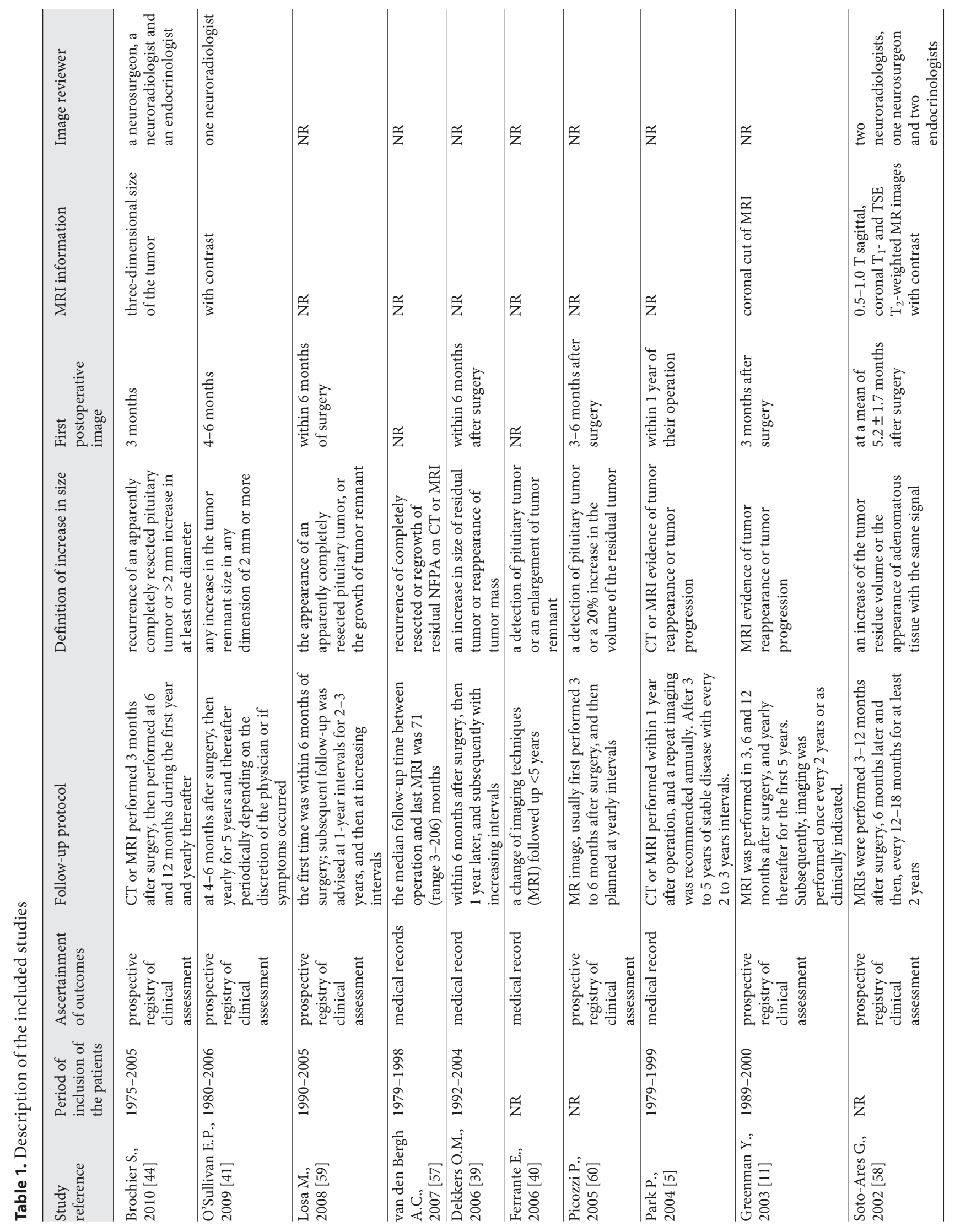




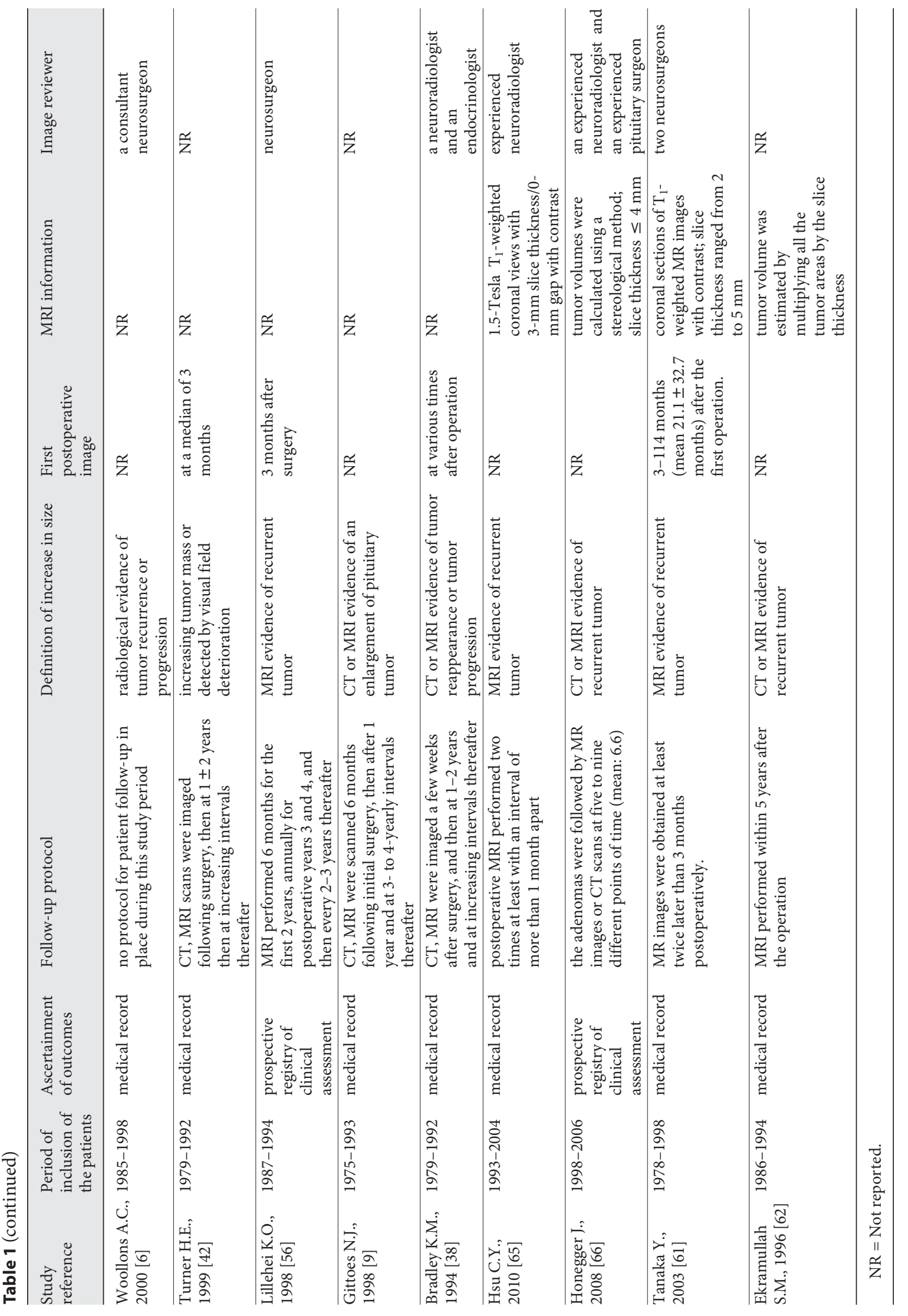




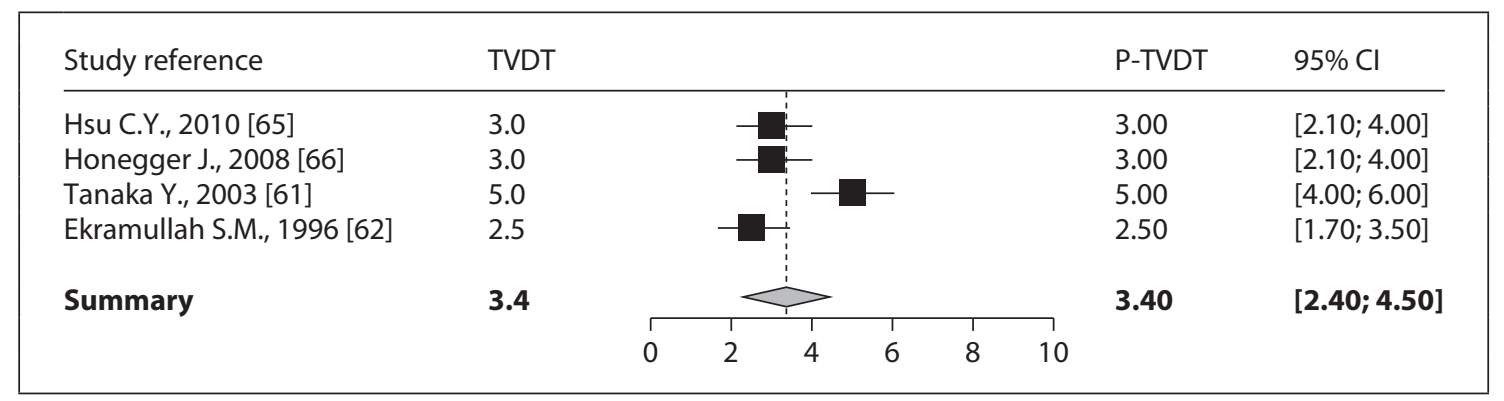

Fig. 2. Residual tumor volume doubling time in 4 studies before 2011 . Test for heterogeneity: $\mathrm{Q}=15.77, \mathrm{p}<$ 0.0013. TVDT $=$ Tumor volume doubling time.

Table 2. Tumor recurrence and tumor growth-free survival rates in 15 studies before 2011

\begin{tabular}{|c|c|c|c|c|c|c|c|c|c|c|c|}
\hline Study reference & $\begin{array}{l}\text { Num- } \\
\text { ber of } \\
\text { cases }\end{array}$ & $\begin{array}{l}\text { Follow-up } \\
\text { time } \\
\text { months }\end{array}$ & total & residual & nonresidual & total & residual & nonresidual & total & residual & nonresidua \\
\hline Brochier S. [44] & 142 & 83 & $56 / 142$ & $10 / 42$ & $47 / 100$ & $75 \%$ & 82 & 70 & $57 \%$ & $68 \%$ & $52 \%$ \\
\hline O'Sullivan E.P. [41] & 126 & 68 & $53 / 126$ & $53 / 100$ & $0 / 26$ & $76 \%$ & 85 or $49 \%^{\S}$ & $100 \%$ & $49 \%$ & 58 or $23 \%^{\dagger}$ & $100 \%$ \\
\hline Losa M. [59] & 355 & 53 & NA/355 & $\mathrm{NA} / 76$ & $\mathrm{NA} / 279$ & NA & $39 \%$ & $87 \%$ & NA & $17 \%$ & $62 \%$ \\
\hline van den Bergh A.C. [57] & 43 & 71 & $17 / 43$ & $16 / 28$ & $1 / 15$ & NA & $49 \%$ & $100 \%$ & NA & $22 \%$ & $67 \%$ \\
\hline Picozzi P. [60] & 68 & 42 & $32 / 68$ & $32 / 68$ & NA & $51 \%$ & $51 \%$ & NA & $51 \%$ & $51 \%$ & NA \\
\hline Park P. [5] & 132 & 45 & $26 / 132$ & NA & NA & $85 \%$ & NA & NA & $50 \%$ & NA & NA \\
\hline Greenman Y. [11] & 108 & 51 & $47 / 108$ & $41 / 78$ & $6 / 30$ & $48 \%$ & $30 \%$ & $84 \%$ & NA & $29 \%$ & $63 \%$ \\
\hline Soto-Ares G. [58] & 51 & 68 & $13 / 51$ & $13 / 34$ & $0 / 17$ & $74 \%$ & $61 \%$ & $100 \%$ & NA & NA & $100 \%$ \\
\hline Woollons A.C. [6] & 22 & 58 & $10 / 22$ & $8 / 11$ & $2 / 11$ & $34 \%$ & $22 \%$ & NA & $34 \%$ & $22 \%$ & NA \\
\hline Turner H.E. [42] & 65 & 76 & $21 / 65$ & $12 / 34$ & $9 / 31$ & $82 \%$ & NA & NA & $56 \%$ & NA & NA \\
\hline
\end{tabular}

$\mathrm{NA}=$ Not available. ${ }^{\S}$ The tumor growth-free survival rates at 5 years were $85 \%$ with intrasellar remnant and $49 \%$ with extrasellar remnant. ${ }^{\dagger}$ The tumor growth-free survival rates at 10 years were $58 \%$ with intrasellar remnant and $23 \%$ with extrasellar remnant.

\section{Meta-Analysis}

Random effects models were computed for all of the growth parameters because tests for heterogeneity probability values were less than 0.01 (table 3 ). The pNFPAs were divided into two groups: group I was composed of patients without detectable postoperative residual tumor (371 patients). The pooled recurrence rate of group I was $12 \%$ (95\% CI 6-19\%). The TGFSR at 5 and 10 years were 96\% (95\% CI 89-99\%) and 82\% (95\% CI 65-94\%). Group II patients were those with residual tumor (600 patients). The pooled recurrence rate of group II was 46\% (95\% CI 36-56\%). The TGFSR at 5 and 10 years were 56\% (95\% CI $41-71 \%)$ and $40 \%$ (95\% CI 27-53\%). The residual TVDT was 3.4 years (95\% CI $2.4-4.5$ years). The pooled tumor recurrence rate was 30\% (95\% CI 23-37\%). The pooled TGFSR at 5 and 10 years were $71 \%$ (95\% CI 59-82\%) and 59\% (95\% CI 47-71\%).

\section{Quality of Studies}

As shown in table 3, all of $\mathrm{I}^{2}$ were greater than $50 \%$, which reflects a large inconsistency among those studies. During the period of inclusion of patients ranging from 1975 to 2006, a few patients of 7 studies used both CT and MRI to assess the tumor volume changes (table 1). Additionally, the majority of studies did not provide enough information about images including whether the images were enhanced or not. The time of first images after surgery widely ranged from 3 to 114 months. First-time im- 
ages were considered as the baseline images, which was important for clinicians to judge the tumor volume changes compared with the follow-up images. An increase in tumor size among those studies was not uniformly defined (more than 2-mm increase in at least one diameter, or a $20 \%$ increase in the volume of the residual tumor, or an enlargement of tumor remnant). Lastly, the images were reviewed by a neuroradiologist and/or neurosurgeon without being carried out in a double-blind fashion. The above aspects might show a large inconsistency.

We conducted the sensitivity analysis by including 4 unqualified studies $[2,10,63,64]$ to determine whether the inclusion of those studies would affect the study conclusions. The pooled tumor recurrence rate was $27 \%$ (95\% CI $21-34 \%)$. The pooled TGFSR at 5 and 10 years were 70\% (95\% CI 58-80\%) and 56\% (95\% CI 43-68\%), respectively.

\section{Discussion}

\section{Principal Findings}

To the best of our knowledge, this is the first systematic review on the natural history of pNFPAs. Because adjunctive treatments as well as follow-up strategy for this condition lack evidence from randomized studies, the results of this meta-analysis will help clinicians make an informed decision about which patients are at sufficient risk of tumor recurrence, who will require postoperative treatment (pituitary radiotherapy) and about which a systematic follow-up strategy is needed.

Through this multicenter meta-analysis, it was found that the pooled rate of gross tumor recurrence was 30\% (95\% CI 23-37\%). In the present study, pNFPAs were divided into two groups. With regard to group I without detectable residual tumor, the pooled recurrence rate was $12 \%$ (95\% CI 6-19\%), the nonresidual TGFSR at 5 and 10 years were 96\% (95\% CI 89-99\%) and 82\% (95\% CI 65$94 \%)$. It shows that the possibility of tumor recurrence is very low in which case postoperative prophylactic radiotherapy is unnecessary, so a 'wait and see' policy is advocated for this group of pNFPAs to prevent unnecessary exposure to potential sequelae of radiotherapy in the majority of patients. However, they still had $12 \%$ recurrence rate which was higher than that of some previous reports $[6,11,38,40,42,43,56,57]$. Except for the routine MRI examination at 3 and 12 months after the initial surgery, the MRI should be repeated not less often than 2, 5 and 10 years or even for a lifelong follow-up in order to verify the absence of late recurrence [67].
Table 3. Incidence of tumor recurrence and TGFSR of pNFPAs

$\begin{array}{lll}\text { Incidence } & \mathrm{I}^{2} & \mathrm{P} \\ \text { and } 95 \% \mathrm{CI} & \end{array}$

Tumor recurrence

$\begin{array}{lllr}\text { Group I } & 12 \%(6-19 \%) & 70.2 \% & 0.0002 \\ \text { Group II } & 46 \%(36-56 \%) & 83.4 \%[70.9 \% ; 90.5 \%] & <0.0001 \\ \text { Overall } & 30 \%(23-37 \%) & 87.1 \%[80 \% ; 91.7 \%] & <0.0001\end{array}$

TGFSR at 5 years

$\begin{array}{llll}\text { Group I } & 96 \%(89-99 \%) & 92.5 \%[87.5 \% ; 95.5 \%] & <0.0001 \\ \text { Group II } & 56 \%(41-71 \%) & 95.9 \%[94.1 \% ; 97.2 \%] & <0.0001 \\ \text { Overall } & 71 \%(59-82 \%) & 94.5 \%[91.7 \% ; 96.3 \%] & <0.0001\end{array}$

TGFSR at 10 years

$\begin{array}{llrl}\text { Group I } & 82 \%(65-94 \%) & 97.1 \%[95.9 \% ; 98 \%] & <0.0001 \\ \text { Group II } & 40 \%(27-53 \%) & 94.1 \%[90.8 \% ; 96.2 \%] & <0.0001 \\ \text { Overall } & 59 \%(47-71 \%) & 93 \%[88.8 \% ; 95.6 \%] & <0.0001\end{array}$

$\mathrm{I}^{2}$ represents the proportion of heterogeneity that is not due to chance. TGFSR $=$ Tumor growth-free survival rate.

On the contrary, in group II with detectable residual tumor, the pooled recurrence rate was $46 \%$ (95\% CI 36$56 \%$ ), that is, about half of pNFPAs with residual tumor had evidence of tumor regrowth. Dekkers' reviews reported that in approximately $50 \%$ nonfunctioning macroadenomas (NFMAs) would develop progression within a 5-year observation period [68]. The TGFSR at 5 and 10 years for group II were 56\% (95\% CI $41-71 \%)$ and $40 \%$ (95\% CI 27-53\%), respectively. This analysis shows that the proportion of residual tumor recurrence is higher and the TGFSR is lower. The optimal treatment strategy in patients of group II is still a challenge. For patients without compression of the optic nerve, treatment decisions should be individualized and should consider age, proximity of the tumor to the chiasm, as well as TVDT. The residual TVDT was 3.4 years through this meta-analysis, i.e. the majority of these tumors grew very slowly, and hence might not reach a large enough volume to impair health within the patient's lifetime, which would provide for an extensive and safe follow-up span. On the other hand, 54\% of residual tumors will not regrow after surgery, so the comprehensive treatment of close follow-up and timely intervention is the optimal choice for the group of residual pNFPAs, in order to reduce the side effects of radiation therapy. We suggest that MRI should be repeated yearly in these patients. Reoperation or radiotherapy should be considered only when the tumoral regrowth is proven, except where the adenomatous residue is voluminous and close to the optic nerves/chiasm [58].

Neuroendocrinology 2012;96:333-342 


\section{Limitations}

From table 2, it becomes evident that the average duration of follow-up in all series is limited to only 42-112 months after surgery (68.71 \pm 5.19 months, mean 5.7 years). Prolongation of the follow-up duration may result in a higher rate of recurrence or regrowth than appreciated by the currently available data. This limitation may bring about the resulting uncertainty (especially TGFSR at 10 years). On the other hand, the nonrandomized, observational nature of the available literature is associated with several methodological issues, including publication bias, reporting bias (not all the outcomes were reported in all papers), and lack of standardization in the study design [46]. These issues highlight the inherent limitations in any meta-analysis based on observational data and the need for future large prospective studies.

\section{Clinical Implications}

In light of very low-quality evidence [47] and the resulting uncertainty, it is suggested that the clinical study should be prospective and use clear and explicit inclusion criteria, objective outcome definitions and assessment, and uniform follow-up. Three suggestions should be considered: firstly, the first-time image after surgery should be obtained 3-4 months after surgery using 1.5or 3.0-Tesla MRI with enhancement $[8,68-70]$; secondly, a uniform follow-up strategy and standard definition of increase in tumor size should be needed, and, thirdly, MR images should be reviewed by an experienced neuroradiologist and neurosurgeon in a double-blind fashion.

\section{Conclusions}

pNFPAs, with or without detectable residual tumor, need stratification of treatment and radiological/endocrinological follow-up strategies. The 'wait and see' policy is the optimal choice for group I pNFPAs. According to the mean TVDT, comprehensive treatment including close follow-up and timely intervention is the reasonable choice for the group II pNFPAs in order to optimize the risk-benefit ratio of postoperative treatment. Clinicians will need to carefully consider the values of very-lowquality evidence, particularly because of the methodological limitations of the included studies and the inconsistent methods and results.

\section{Acknowledgement}

We are grateful to Edward Laws (Department of Neurosurgery, Brigham and Women's Hospital, Boston, Mass., USA) for his critical evaluation and linguistic revision of the manuscript.

\section{Grand Support}

This project was based upon work funded by grants from the National Natural Science Foundation of China (30800347), by Zhejiang Povincial Natural Science Foundation of China under Grant No. R2091137 and Zhejiang Provincial Program for the Cultivation of High-level Innovative Health talents.

\section{Disclosure Statement}

The authors have nothing to declare.

\section{References}

1 Laws ER Jr, Vance ML: Radiosurgery for pituitary tumors and craniopharyngiomas. Neurosurg Clin N Am 1999;10:327-336.

-2 Mortini P, Barzaghi R, Losa M, Boari N, Giovanelli M: Surgical treatment of giant pituitary adenomas: strategies and results in a series of 95 consecutive patients. Neurosurgery 2007;60:993-1002.

-3 Comtois R, Beauregard H, Somma M, Serri O, Aris-Jilwan N, Hardy J: The clinical and endocrine outcome to trans-sphenoidal microsurgery of nonsecreting pituitary adenomas. Cancer 1991;68:860-866.

-4 Ebersold MJ QL, Laws ER Jr, Scheithauer B, Randall RV: Long-term results in transsphenoidal removal of nonfunctioning pituitary adenomas. J Neurosurg 1986;64:713-719.
-5 Park P, Chandler WF, Barkan AL, Orrego JJ, Cowan JA, Griffith KA, Tsien C: The role of radiation therapy after surgical resection of nonfunctional pituitary macroadenomas. Neurosurgery 2004;55:100-106.

-6 Woollons AC, Hunn MK, Rajapakse YR, Toomath R, Hamilton DA, Conaglen JV, Balakrishnan V: Non-functioning pituitary adenomas: Indications for postoperative radiotherapy. Clin Endocrinol (Oxf) 2000;53: 713-717.

7 Colao A, Di Somma C, Pivonello R, Faggiano A, Lombardi G, Savastano S: Medical therapy for clinically non-functioning pituitary adenomas. Endocr Relat Cancer 2008; 15: 905-915.
8 Greenman Y, Tordjman K, Osher E, Veshchev I, Shenkerman G, Reider G II, Segev Y, Ouaknine G, Stern N: Postoperative treatment of clinically nonfunctioning pituitary adenomas with dopamine agonists decreases tumour remnant growth. Clin Endocrinol (Oxf) 2005;63:39-44.

$\$ 9$ Gittoes NJ, Bates AS, Tse W, Bullivant B, Sheppard MC, Clayton RN, Stewart PM: Radiotherapy for non-function pituitary tumours. Clin Endocrinol (Oxf) 1998;48:331337.

10 Alameda C, Lucas T, Pineda E, Brito M, Uria JG, Magallon R, Estrada J, Barcelo B: Experience in management of 51 non-functioning pituitary adenomas: indications for post-operative radiotherapy. J Endocrinol Invest 2005;28:18-22. 
11 Greenman Y, Ouaknine G, Veshchev I, Reider G II, Segev Y, Stern N: Postoperative surveillance of clinically nonfunctioning pituitary macroadenomas: Markers of tumour quiescence and regrowth. Clin Endocrinol (Oxf) 2003;58:763-769.

$\checkmark 12$ Grigsby PW, Simpson JR, Fineberg B: Late regrowth of pituitary adenomas after irradiation and/or surgery. Hazard function analysis. Cancer 1989;63:1308-1312.

-13 Brada M, Rajan B, Traish D, Ashley S, Holmes-Sellors PJ, Nussey S, Uttley D: The long-term efficacy of conservative surgery and radiotherapy in the control of pituitary adenomas. Clin Endocrinol (Oxf) 1993;38: 571-578.

-14 Tsang RW, Brierley JD, Panzarella T, Gospodarowicz MK, Sutcliffe SB, Simpson WJ: Radiation therapy for pituitary adenoma: treatment outcome and prognostic factors. Int $J$ Radiat Oncol Biol Phys 1994;30:557-565.

$\checkmark 15$ Zierhut D FM, Adolph J, Erdmann J, Raue F, Wannenmacher M: External radiotherapy of pituitary adenomas. Int J Radiat Oncol Biol Phys 1995;33:307-314.

- 16 Flickinger JC, Nelson PB, Martinez AJ, Deutsch M, Taylor F: Radiotherapy of nonfunctional adenomas of the pituitary gland. Results with long-term follow-up. Cancer 1989;63:2409-2414.

$\checkmark 17$ Breen P, Flickinger JC, Kondziolka D, Martinez AJ: Radiotherapy for nonfunctional pituitary adenoma: analysis of long-term tumor control. J Neurosurg 1998;89:933-938.

-18 Fernandez A, Brada M, Zabuliene L, Karavitaki N, Wass JA: Radiation-induced hypopituitarism. Endocr Relat Cancer 2009;16: 733-772.

19 McCord MW, Buatti JM, Fennell EM, Mendenhall WM, Marcus RB Jr, Rhoton AL, Grant MB, Friedman WA: Radiotherapy for pituitary adenoma: long-term outcome and sequelae. Int J Radiat Oncol Biol Phys 1997; 39:437-444.

20 Rush S, Cooper PR: Symptom resolution, tumor control, and side effects following postoperative radiotherapy for pituitary macroadenomas. Int J Radiat Oncol Biol Phys 1997;37:1031-1034.

-21 al-Mefty O, Kersh JE, Routh A, Smith RR: The long-term side effects of radiation therapy for benign brain tumors in adults. J Neurosurg 1990;73:502-512.

-22 Brada M, Ford D, Ashley S, Bliss JM, Crowley S, Mason M, Rajan B, Traish D: Risk of second brain tumour after conservative surgery and radiotherapy for pituitary adenoma. BMJ 1992;304:1343-1346.

23 Brada M, Ashley S, Ford D, Traish D, Burchell L, Rajan B: Cerebrovascular mortality in patients with pituitary adenoma. Clin Endocrinol (Oxf) 2002;57:713-717.
24 Erfurth EM, Bulow B, Svahn-Tapper G, Norrving B, Odh K, Mikoczy Z, Bjork J, Hagmar L: Risk factors for cerebrovascular deaths in patients operated and irradiated for pituitary tumors. J Clin Endocrinol Metab 2002;87:4892-4899.

25 Hahn CA, Zhou SM, Raynor R, Tisch A, Light K, Shafman T, Wong T, Kirkpatrick J, Turkington T, Hollis D, Marks LB: Dose-dependent effects of radiation therapy on cerebral blood flow, metabolism, and neurocognitive dysfunction. Int J Radiat Oncol Biol Phys 2009;73:1082-1087.

26 Tsang RW, Laperriere NJ, Simpson WJ, Brierley J, Panzarella T, Smyth HS: Glioma arising after radiation therapy for pituitary adenoma. A report of four patients and estimation of risk. Cancer 1993;72:2227-2233.

27 Minniti G, Traish D, Ashley S, Gonsalves A, Brada M: Risk of second brain tumor after conservative surgery and radiotherapy for pituitary adenoma: update after an additional 10 years. J Clin Endocrinol Metab 2005;90: 800-804.

-28 Muacevic A, Uhl E, Wowra B: Gamma knife radiosurgery for nonfunctioning pituitary adenomas. Acta Neurochir Suppl 2004;91: 51-54.

29 Sheehan JP, Kondziolka D, Flickinger J, Lunsford LD: Radiosurgery for residual or recurrent nonfunctioning pituitary adenoma. J Neurosurg 2002;97:408-414.

-30 Sheehan JP, Kondziolka D, Flickinger J, Lunsford LD: Radiosurgery for nonfunctioning pituitary adenoma. Neurosurg Focus 2003; 14:e9.

- 31 Sheehan JP, Niranjan A, Sheehan JM, Jane JA Jr, Laws ER, Kondziolka D, Flickinger J, Landolt AM, Loeffler JS, Lunsford LD: Stereotactic radiosurgery for pituitary adenomas: an intermediate review of its safety, efficacy, and role in the neurosurgical treatment armamentarium. J Neurosurg 2005; 102:678-691.

32 Minniti G, Traish D, Ashley S, Gonsalves A, Brada M: Fractionated stereotactic conformal radiotherapy for secreting and nonsecreting pituitary adenomas. Clin Endocrinol (Oxf) 2006;64:542-548.

33 Pollock BE, Cochran J, Natt N, Brown PD, Erickson D, Link MJ, Garces YI, Foote RL, Stafford SL, Schomberg PJ: Gamma knife radiosurgery for patients with nonfunctioning pituitary adenomas: results from a 15-year experience. Int J Radiat Oncol Biol Phys 2008;70:1325-1329.

-34 Losa M, Valle M, Mortini P, Franzin A, da Passano CF, Cenzato M, Bianchi S, Picozzi P, Giovanelli M: Gamma knife surgery for treatment of residual nonfunctioning pituitary adenomas after surgical debulking. J Neurosurg 2004;100:438-444.
35 Jagannathan J, Yen CP, Pouratian N, Laws ER, Sheehan JP: Stereotactic radiosurgery for pituitary adenomas: a comprehensive review of indications, techniques and longterm results using the gamma knife. J Neurooncol 2009;92:345-356.

36 Ganz JC: Gamma knife radiosurgery and its possible relationship to malignancy: a review. J Neurosurg 2002;97:644-652.

-37 Minniti G, Jaffrain-Rea ML, Osti M, Cantore G, Enrici RM: Radiotherapy for nonfunctioning pituitary adenomas: from conventional to modern stereotactic radiation techniques. Neurosurg Rev 2007;30:167-175; discussion 175-166.

38 Bradley KM, Adams CB, Potter CP, Wheeler DW, Anslow PJ, Burke CW: An audit of selected patients with non-functioning pituitary adenoma treated by transsphenoidal surgery without irradiation. Clin Endocrinol (Oxf) 1994;41:655-659.

- 39 Dekkers OM, Pereira AM, Roelfsema F, Voormolen JH, Neelis KJ, Schroijen MA, Smit JW, Romijn JA: Observation alone after transsphenoidal surgery for nonfunctioning pituitary macroadenoma. J Clin Endocrinol Metab 2006;91:1796-1801.

40 Ferrante E, Ferraroni M, Castrignano T, Menicatti L, Anagni M, Reimondo G, Del Monte P, Bernasconi D, Loli P, Faustini-Fustini M, Borretta G, Terzolo M, Losa M, Morabito A, Spada A, Beck-Peccoz P, Lania AG: Nonfunctioning pituitary adenoma database: a useful resource to improve the clinical management of pituitary tumors. Eur J Endocrinol 2006;155:823-829.

41 O'Sullivan EP, Woods C, Glynn N, Behan LA, Crowley R, O'Kelly P, Smith D, Thompson CJ, Agha A: The natural history of surgically treated but radiotherapy-naive nonfunctioning pituitary adenomas. Clin Endocrinol (Oxf) 2009;71:709-714.

42 Turner HE, Stratton IM, Byrne JV, Adams CB, Wass JA: Audit of selected patients with nonfunctioning pituitary adenomas treated without irradiation - a follow-up study. Clin Endocrinol (Oxf) 1999:51:281-284

-43 van Lindert EJ, Grotenhuis JA, Meijer E: Results of follow-up after removal of non-functioning pituitary adenomas by transcranial surgery. Br J Neurosurg 1991;5:129-133.

- 44 Brochier S, Galland F, Kujas M, Parker F, Gaillard S, Raftopoulos C, Young J, Alexopoulou $\mathrm{O}$, Maiter D, Chanson P: Factors predicting relapse of nonfunctioning pituitary macroadenomas after neurosurgery: a study of 142 patients. Eur J Endocrinol 2010;163: 193-200.

45 Moher D, Liberati A, Tetzlaff J, Altman DG: Preferred reporting items for systematic reviews and meta-analyses: the prisma statement. Ann Intern Med 2009;151:264-269, W264. 
-46 Stroup DF, Berlin JA, Morton SC, Olkin I, Williamson GD, Rennie D, Moher D, Becker BJ, Sipe TA, Thacker SB: Meta-analysis of observational studies in epidemiology: a proposal for reporting. Meta-analysis Of Observational Studies in Epidemiology (MOOSE) group. JAMA 2000;283:2008-2012.

47 Swiglo BA, Murad MH, Schunemann HJ, Kunz R, Vigersky RA, Guyatt GH, Montori VM: A case for clarity, consistency, and helpfulness: state-of-the-art clinical practice guidelines in endocrinology using the grading of recommendations, assessment, development, and evaluation system. J Clin Endocrinol Metab 2008;93:666-673.

-48 Fernandez-Balsells MM, Murad MH, Barwise A, Gallegos-Orozco JF, Paul A, Lane MA, Lampropulos JF, Natividad I, PeresteloPerez L, Ponce de Leon-Lovaton PG, Erwin PJ, Carey J, Montori VM: Natural history of nonfunctioning pituitary adenomas and incidentalomas: a systematic review and metaanalysis. J Clin Endocrinol Metab 2011;96: 905-912.

49 DerSimonian RLN: Meta-analysis in clinical trials. Control Clin Trials 1986;7:177-188.

50 Ciric I, Mikhael M, Stafford T, Lawson L, Garces R: Transsphenoidal microsurgery of pituitary macroadenomas with long-term follow-up results. J Neurosurg 1983;59:395401.

51 Halberg FS G: Radiotherapy ofpituitary tumours. Endocrinol Metab Clin 1987;7:667668.

52 Chun M MG, Hetelekidis S: Radiotherapy in the treatment of pituitary adenomas. Int $J$ Radiat Oncol Biol Phys 1988;15:305-309.

53 Vlahovitch B, Reynaud C, Rhiati J, Mansour $\mathrm{H}$, Hammoud F: Treatment and recurrences in 135 pituitary adenomas. Acta Neurochir Suppl (Wien) 1988;42:120-123.
54 Shone GR, Richards SH, Hourihan MD, Hall R, Thomas JP, Scanlon MF: Non-secretory adenomas of the pituitary treated by transethmoidal sellotomy. J R Soc Med 1991;84: 140-143.

55 Sassolas G TJ, Treluyer C, Perrin G: Management of nonfunctioning pituitary adenomas. Acta Endocrinol (Copenh) 1993;129(suppl 1):21-26.

56 Lillehei KO, Kirschman DL, KleinschmidtDe Masters BK, Ridgway EC: Reassessment of the role of radiation therapy in the treatment of endocrine-inactive pituitary macroadenomas. Neurosurgery 1998;43:432438.

7 van den Bergh AC, van den Berg G, Schoorl MA, Sluiter WJ, van der Vliet AM, Hoving EW, Szabo BG, Langendijk JA, Wolffenbuttel $\mathrm{BH}$, Dullaart RP: Immediate postoperative radiotherapy in residual nonfunctioning pituitary adenoma: beneficial effect on local control without additional negative impact on pituitary function and life expectancy. Int J Radiat Oncol Biol Phys 2007;67:863-869.

58 Soto-Ares G, Cortet-Rudelli C, Assaker R, Boulinguez A, Dubest C, Dewailly D, Pruvo JP: MRI protocol technique in the optimal therapeutic strategy of non-functioning pituitary adenomas. Eur J Endocrinol 2002; 146:179-186.

-59 Losa M, Mortini P, Barzaghi R, Ribotto P, Terreni MR, Marzoli SB, Pieralli S, Giovanelli M: Early results of surgery in patients with nonfunctioning pituitary adenoma and analysis of the risk of tumor recurrence. J Neurosurg 2008;108:525-532.

60 Picozzi P, Losa M, Mortini P, Valle MA, Franzin A, Attuati L, Ferrari da Passano C, Giovanelli M: Radiosurgery and the prevention of regrowth of incompletely removed nonfunctioning pituitary adenomas. J Neurosurg 2005;102(suppl):71-74.

61 Tanaka Y, Hongo K, Tada T, Sakai K, Kakizawa Y, Kobayashi S: Growth pattern and rate in residual nonfunctioning pituitary adenomas: Correlations among tumor volume doubling time, patient age, and mib-1 index. J Neurosurg 2003;98:359-365.
62 Ekramullah SM, Saitoh Y, Arita N, Ohnishi T, Hayakawa T: The correlation of ki- 67 staining indices with tumour doubling times in regrowing non-functioning pituitary adenomas. Acta Neurochir (Wien) 1996;138: 1449-1455.

63 Coulter IC, Mukerji N, Bradey N, Connolly V, Kane PJ: Radiologic follow-up of nonfunctioning pituitary adenomas: rationale and cost effectiveness. J Neurooncol 2009;93: 157-163.

64 Zhang X, Fei Z, Zhang J, Fu L, Zhang Z, Liu W, Chen Y: Management of nonfunctioning pituitary adenomas with suprasellar extensions by transsphenoidal microsurgery. Surg Neurol 1999;52:380-385.

65 Hsu CY, Guo WY, Chien CP, Ho DM: Mib-1 labeling index correlated with magnetic resonance imaging detected tumor volume doubling time in pituitary adenoma. Eur J Endocrinol 2010;162:1027-1033.

66 Honegger J, Zimmermann S, Psaras T, Petrick M, Mittelbronn M, Ernemann U, Reincke M, Dietz K: Growth modelling of non-functioning pituitary adenomas in patients referred for surgery. Eur J Endocrinol 2008;158:287-294.

67 Greenman Y, Stern N: How should a nonfunctioning pituitary macroadenoma be monitored after debulking surgery? Clin Endocrinol (Oxf) 2009;70:829-832.

68 Dekkers OM, Pereira AM, Romijn JA: Treatment and follow-up of clinically nonfunctioning pituitary macroadenomas. J Clin Endocrinol Metab 2008;93:3717-3726.

69 Greenman Y, Stern N: Non-functioning pituitary adenomas. Best Pract Res Clin Endocrinol Metab 2009;23:625-638.

70 Molitch ME: Nonfunctioning pituitary tumors and pituitary incidentalomas. Endocrinol Metab Clin North Am 2008;37:151171. 